\title{
El TRABAJO SOCIAL Y LA IDENTIDAD PROFESIONAL*
}

Nora Aquín 


\title{
RESUMEN
}

\begin{abstract}
La autora inicia con una pregunta: Porqué la preocupación recurrente en torno a nuestra identidad, en distintas latitudes y en distintos momentos históricos? Su hipótesis es que la poca valoración que nos han dado en el campo de las ciencias sociales nos ha llevado a la búsqueda de un reconocimiento que se ha vuelto problemático por cuanto el mismo concepto de identidad es inestable y poco preciso. En este sentido desarrolla tres ideas centrales: Una conceptualización de la categoría de identidad, una reflexión en tomo al problema de las identidades en Trabajo Social y algunas propuestas para afrontar el presente y el futuro.
\end{abstract}

$i$ Por qué la preocupación recurrente en torno a nuestra identidad, en distintas latitudes y en distintos momentos históricos? Mi hipótesis es que el grado y nivel de preocupación por nuestra identidad es inversamente proporcional al grado de reconocimiento social alcanzado por nuestra disciplina. Nos sucede, en este sentido, lo mismo que ocurre con los seres humanos: la identidad cultural, étnica, sexual, etc., es preocupación de los grupos más vulnerados y vulnerables, porque es vivida como una experiencia traumática y como una herida narcisística, es decir, una herida a la autovaloración. El Trabajo Social y los trabajadores sociales estamos permanentemente heridos en nuestra autovaloración, en tanto ocupamos un lugar subordinado y muy vulnerable en el campo de las Ciencias Sociales, y no hemos alcanzado todavía el reconocimiento que creemos merecer. De esta manera, se constituye un campo de extrema tensión entre lo que nosotros consideramos que nos corresponde y lo que los otros están dispuestos a concedernos. En términos hegelianos, "las identidades que no son reconocidas por aquellos con los que nuestras vidas y destinos están trabados, son inherentemente inestables".

Precisamente, el mismo concepto de identidad es inestable y problemático. Y ello, a pesar de que hoy cotice muy alto en el mercado de las ciencias sociales, hasta el punto que ya hay quienes hablan de los empresarios de la identidad.

Es desde esta hipótesis, y a la vez desde esta advertencia de un cierto proceso de "mercantilización” del problema de la identidad, que me propongo exponer en esta

* Trabajo presentado en XII Congreso Colombiano de Trabajo Social realizado en Manizales del 19 al 22 de agosto de 2003. 
ocasión las siguientes tres cuestiones:

- Una conceptualización de la categoría de identidad

- Una reflexión en tomo al problema de las identidades en Trabajo Social.

- Algunas propuestas para afrontar el presente y el futuro

\section{1.- ACERCA DEL CONCEPTO DE IDENTIDAD.-}

¿Qué es la identidad? ¿Un atributo? ¿Un sentimiento? ¿Un proceso? Precisamente las perspectivas de análisis se dividen según como respondan a estos interrogantes ${ }^{1}$.

Quienes asumen una perspectiva objetivista en el análisis de la identidad, dirán de la identidad que es un dato que define para siempre al individuo, como una segunda naturaleza a la que se adhiere a partir de una pertenencia cultural originaria. En esta perspectiva, la identidad aparece como una esencia estable y definitiva, al margen de cualquier evolución, y sobre la cual ni el individuo ni el grupo tienen influencia alguna.

Quienes se inscriben en la perspectiva culturalista pondrán el acento en la herencia cultural derivada del proceso de socialización del individuo en su grupo, afirmando que la identidad se conforma a través de la interiorización de modelos culturales impuestos, y por lo tanto la identidad es considerada como consustancial con una cultura particular y preexistente al individuo.

Por su parte, los etnoculturalistas sostendrán que, siendo la pertenencia a un grupo la primera y más fundamental de todas las pertenencias sociales, la identidad debe ser comprendida como una propiedad esencial inherente ya no al individuo sino al grupo.

Es la perspectiva subjetivista la que, en confrontación con las posiciones anteriores, sostendrá que la identidad no puede ser reducida a atributos, sino que debe ser entendida como un sentimiento de identificación con una colectividad más o menos imaginaria.

Lo que cuenta son las representaciones que los individuos construyen de una cierta realidad social. Aquí predomina el reconocimiento del carácter más variable y efímero de la identidad, que rompe con la visión esencialista y pone el énfasis en la elección identitaria individual. Su quintaesencia radica en la "conciencia de pertenencia" a una comunidad singular, o bien en el "sentimiento de pertenencia" y adscripción, con lo que las raíces se hunden en lo inconsciente.

Queremos someter a una breve crítica las posiciones hasta aquí enunciadas, para luego proponer una perspectiva para analizar la identidad. Tanto en el objetivismo como en el culturalismo y el etnoculturalismo, encontramos una concepción esencialista y objetivista de la identidad. La misma suele ser definida como un conjunto de rasgos y características que portan sujetos, grupos, comunidades o pueblos, y que los diferencian de otros. Abordar la problemática de la identidad desde esta perspectiva, implica correr

${ }^{1}$ Sigo en este aspecto los aportes de Acevedo P. La fuerza del origen. Tesis para acceder al Título de Magister en Ciencias. Escuela de Trabajo Social. Universidad Nacional de Córdoba. 2003. 
el riesgo de incurrir nuevamente en una ontologización de las diferencias.

Por su parte, la perspectiva subjetivista, si bien no incurre en el reduccionismo de la identidad a los atributos, sí la reduce al sentimiento. Creemos que al colocar la mayor parte del peso de la identidad en los sentimientos, termina considerando al sentimiento como un dato originario, genuino y primordial. Queremos proponer, por lo tanto, un enfoque de la identidad en una perspectiva relacionar y situacional, que se aleja de su identificación como simple dato, para considerarla como una construcción social, fruto de procesos de interacción en el marco de contextos y situaciones cambiantes. En esta perspectiva, la construcción de identidad es un proceso que tiene lugar dentro de marcos en los que distintos agentes ocupan distintas posiciones, y por lo mismo tienen diferentes representaciones y opciones. Lejos de la posición subjetivista, la identidad en esta perspectiva, no es una ilusión, sino que tiene eficacia social, en tanto produce efectos sociales reales. De manera que es posible afirmar que "la identidad no es, sino que se genera lenta e históricamente, y se constituye mediante una red de vinculos medianamente estables y significativos, y relaciones que las sustentan desde estas relaciones y representaciones un sujeto (individual o colectivo) construye su auto imagen y la imagen del otro, o los otros ${ }^{2}$.

Por lo tanto:

- La identidad es un proceso de identificaciones históricamente apropiadas que confieren sentido a un grupo social y le dan estructura significativa para asumirse como unidad ${ }^{3}$.

- La identidad es un fenómeno relacional y un modo de categorización que los grupos utilizan para organizar sus intercambios.

- Considerar la identidad de un grupo no equivale a concretar el inventario de sus rasgos culturales distintivos, sino encontrar en estos rasgos los que son empleados por los miembros del grupo para afirmar y mantener una distinción cultural.

- La composición de las identidades colectivas es heterogéneo, abierta, dispuesta al cambio, ya que suponen un proceso permanente que se mueve entre el "ser" llegar a ser”, porque siempre son relativas a algo, un algo que es histórico y social. De ahí que la identidad, en un doble movimiento, tiende al mismo tiempo a la preservación y a la recreación.

- La identidad supone ineludiblemente otro. En este sentido, Marc Auge sostiene que "el lenguaje de la identidad es un lenguaje bivalente, lenguaje de la inclusión y la exclusión Esta concepción implica situar la problemática de la identidad en torno a las relaciones con otros y al proceso de constitución, transmisión, mantenimiento y recreación,

\footnotetext{
23.

${ }^{2}$ Parisí A. et al: Nuevos sujetos socwes. Identidad y Cultum Espacio Editoñg Buenos, 1995, pág.

${ }^{3}$ Díaz Cruz, R.: Experiencias de la identidad. UNAM, México, 2000.

${ }^{4}$ Auge, M (1998), Los no lugares del anonimato -Una antropología de la sobremodemidadGedisa, Barcelona, España.
} 
y no en la búsqueda de una incierta esencia que la definirla. Desde esta perspectiva no bay identidad en sí, ni únicamente para sí. Identidad y alteridad están ligadas en una relación dialéctica". De este modo, identificación y distinción son las dos caras de la misma moneda

\section{2.- IMPLICANCIAS PARA EL TRABAJO SOCIAL -}

\section{¿Qué le dicen los conceptos discutidos basta abora al Trabajo Social?}

Si nos pensamos como colectivo profesional, tendremos necesariamente que apelar a la dimensión social o colectiva de la identidad, identidad que es una dimensión significante de nuestra práctica social, y que expresa la autoadscripción a una categoría social diferenciada, para nuestro caso el Trabajo Social. La identidad social traza fronteras a partir de las cuales se producen procesos de inclusión, de exclusión y de diferenciación. La identidad nos permite organizar intercambios y contar -también contarnos- nuestra historia. Quizá el aspecto más conflictivo de la identidad social del Trabajo Social no radique tanto en los procesos de inclusión o exclusión, como en el de diferenciación. ¿En qué grado y con qué intensidad logramos diferenciarnos con otros grupos, profesionales o no, con los que tenemos relaciones de distinto orden? ¿Qué grado y qué intensidad de pertenencia y de certidumbre hemos alcanzado como parte de nuestro colectivo? ¿Es importante alcanzar seguridad en cuanto a nuestra pertenencia y en cuanto a nuestras certidumbres?

Precisamente, algunos autores ${ }^{5}$ sostienen que hay tres atributos fundamentales de la identidad, que se traducen en pertenencia y certidumbre para los integrantes de un grupo:

- La identidad otorga a los componentes de un grupo permanencia, es decir, puntos más o menos fijos de referencia, a partir de los cuales se puede mantener la expectativa cierta de que se actuará de cierta forma.

- La identidad circunscribe la unidad y cohesión de un grupo, marcando las fronteras de su yo, y le da la certeza de un estado separado -para nuestro caso una profesión específica- que tiene sentido y justificación.

- La identidad proporciona la posibilidad de relacionarnos con otros desde un lugar propio.

Para el Trabajo Social, estas dimensiones constitutivas de la identidad social deberían, quizá, invitamos a pensar, entre otras cosas, qué ocurre al interior de nuestro colectivo con la reciprocidad, con las fronteras disciplinarias, con nuestras expectativas, con nuestro habitus profesional, y si estas marcas han contribuido a la constitución de una identidad positiva o negativa. $\mathrm{Y}$ entonces recordemos la conjetura que planteábamos al comienzo:

${ }^{5}$ París Pombo, M. (1 990) Crisis e Identidades Colectivas en América Latina, México. 
nuestra preocupación por la identidad es inversamente proporcional al grado de reconocimiento social alcanzado. En términos de autores reconocidos, Kymlicka ${ }^{6}$ advertirá que la seguridad es relativa a la estima que el grupo de pertenencia tenga. Otros autores, refiriéndose a grupos culturales, sostienen argumentos similares al plantear que "si una cultura no goza de respeto general, entonces la dignidad y el respeto a sí mismos de sus miembros están amenazados "(Taylor, 1992) (Tamir, 1993, Margaliz y Taz, 1990)7.

Como señala Pierre Bourdieu en su artículo "La identidad y la representación" solo aquellos que disponen de autoridad legitima, es decir autoridad que confiere el poder, son quienes pueden imponer sus propias definiciones de ellos mismos y de los otros. De quienes son los unos, y de cómo son, y de quiénes son los otros, y de cómo son " (Bourdícu, 1980 pag. 125).

$¿$ ¿Ha podido hasta ahora el Trabajo Social disponer de la autoridad legítima necesaria, en base a su propio poder, para imponer sus propias definiciones de sí mismo? ¿Ha podido definir quiénes son los unos y cómo son, y quienes son los otros y cómo son? Creemos firmemente que no. Vienen a mi memoria, en este sentido, algunas designaciones identitarias a través de las cuales autores consagrados -y por lo tanto con legitimidad y poder- designar a los trabajadores sociales: en ese discurso, aparecemos como bomberos del Estado, fiscalizadores de la pobreza, policías de las familias, agentes de control social. No quisiera soslayar la evidencia de que esta atribución de identidad nos ha colocado fuertemente en el polo del Estado -bomberos, fiscales, policías- pero simultáneamente desde el polo de la negatividad.

Por otra parte, la mirada de los sectores con los que mayoritariamente trabajamos, se presenta como una extensión de la imagen benefactora con que el Estado se ha presentado históricamente frente a la sociedad: somos algo así como los guardianes de la justicia, detentores de una ética incorruptible, casi celestial, y por lo tanto de baja densidad profesional.

Entre estas dos atribuciones de identidad, nuestra autorrepresentación gira generalmente alrededor de un discurso grandilocuente, poblado de llamados a la buena voluntad y al compromiso, que quizá funcione como utopías compensatorias que contrarresten las angustias y el desamparo a que nos somete muchas veces la práctica profesional cotidiana. Generalmente, se trata de un discurso que no arroja suficiente luz sobre nuestro propio quehacer específico. Estas distintas atribuciones de identidad, por parte de los unos y los otros, concomitante a nuestro escaso poder para imponer el discurso acerca de quiénes somos, produce tensiones y conflictos muy marcados, que se expresan, entre otras, en la pregunta en torno a quiénes somos, en definitiva. Y en tanto soporte de nuestra intervención, suelen jugarnos malas pasadas y algunos enredos, que muchas veces oscurecen la aprehensión del significado real de nuestra práctica, aún por nosotros mismos. De ahí mi hipótesis inicial, en cuanto a que el grado y nivel de

\footnotetext{
${ }^{6}$ Kymlieka, W. (1 996) Ciudadanía Multicultural, Paidés -Estado y Sociedad- Barcelona, España.

${ }^{7}$ Citados en Kymlieka, W. (1 996).
} 
preocupación por nuestra identidad es inversamente proporcional al grado de reconocimiento social alcanzado por nuestra disciplina.

Muchas veces, nuestro propio discurso que atribuye determinados atributos a nuestra identidad, deja de lado el hecho de que el sentido y direccionalidad de las profesiones, se define no sólo por contenidos discursivos, y mucho menos por la sola voluntad de los agentes profesionales, sino que se define por su inserción en la dinámica social como una práctica social específica, condicionada por determinaciones objetivas y por una determinada correlación de fuerzas.

En una mirada sincrónica, aquí y ahora la correlación de fuerzas ha violentado nuestras bases materiales y simbólicas de sustentación: la privatización de la cuestión social, la psicologización y juridización de los problemas sociales, la criminalización de la pobreza, el aumento de los requisitos en los parámetros de eficiencia y productividad, lo que en Argentina llamamos "contratos basura" cada uno de ellos ha golpeado y ha dejado marcas en la identidad precariamente construida.

Por otra parte, en una mirada diacrónico, entre nuestros primeros agentes de intervención social, mujeres con una posición favorable en el espacio social, y el nuevo perfil del trabajador social, ha corrido, sin dudas, mucho agua bajo el puente. Aquellas pioneras basaban su accionar en la idea de sujetos cuya condición era un pecado, un accidente o una fatalidad, en cualquier caso riesgoso porque producían fracturas sociales que requerían de soluciones individualizadas, con base en la educación, la asistencia, la higiene y la moral. El nuevo perfil de trabajador social que pugna por imponerse abarca a sujetos unidos de un cotizado capital social y técnico, con experiencias diversificadas, positivamente predispuesto al trabajo autónomo, ideológicamente afín al pragmatismo, con exigencias de metas calculadas y eficiencia en base a la relación costo-beneficio. En el tránsito entre estos dos perfiles hemos probado ser expertos en desarrollo, concientizadores, educadores populares. Hemos atravesado crisis, se han redefinido categorías, han estallado nuestras identidades. Estos momentos históricos se diferencian entre sí por muchas razones, pero la pregunta por la identidad se ha mantenido constante.

Por otra parte, la pregunta por la identidad ha provocado distintas posiciones que han entablado entre sí una lucha de sentidos, de manera que para el Trabajo Social tampoco podemos hablar de una identidad única e inmutable, sino de identidades que pugnan por imponerse. En esta perspectiva, ya no habría espacio para hablar de una identidad en singular, sino de identidades plurales, siempre habitadas por procesos de conservación, de superación y de ruptura. Estos tres procesos provocan que en cada momento histórico podamos percibir que a la vez, y simultáneamente, somos y no somos los mismos. Existen distintas y hasta contradictorias imágenes de lo que es el Trabajo Social, aún

\footnotetext{
${ }^{8}$ En distintos planes sociales, los trabajadores sociales que operan en ellos reciben como retribución económica de su ejercicio... un «beneficio» idéntico al otorgado a los beneficiarios de los planes. Es de suponer que en estos pequños espacios se juega con fuerza la cuestión de la identidad.
} 
entre los mismos profesionales. La profesión se piensa y se ejerce desde el gremio, que generalmente se piensa desde el "ser", y también desde la academia, que generalmente se piensa desde el "deber ser". Ambas instancias, por momentos divorciadas, por momentos articuladas, por momentos mimetizadas, son espacios privilegiados en los procesos de constitución de nuestra identidad profesional. En este marco, cada momento en que a través de la construcción de nuestra identidad hemos ordenado nuestra propia historia, produjo rupturas y cimbronazos, superó aspectos y fue dejando su impronta en la historia de nuestra propia consolidación.

¿Cuál es la impronta, que a mi criterio, se ha ido sedimentando en nuestra historia y que hace que, finalmente, seamos los mismos?

En primer lugar, la constatación de que los trabajadores sociales intervenimos en los subsuelos, en las orillas, con los históricos condenados de la tierra. Condenados no sólo desde una perspectiva económica, sino también considerando aspectos afectivos y vinculares.

En segundo lugar, nuestra vinculación con los derechos sociales de ciudadanía, concebidos como espacios de construcción de sujetos que se emancipan de las limitaciones básicas que su condición le impone a su disposición.

En tercer lugar, es posible hablar de un campo de intervención pertinente a nuestra disciplina que se delimita recuperando ciertas constantes de las diferentes lógicas del campo social, y que se estructura como campo profesional. Es decir, hay un núcleo duro de nuestra identidad que se mantiene. Ese núcleo duro radica en que el Trabajo Social es al mismo tiempo una práctica distributiva y una práctica cultural. Decimos que es una práctica distributiva, en el sentido de distribución de valores de uso entre individuos, grupos e instancias sociales, cuyo objetivo es lograr una distribución deseada. Y decimos que es una práctica cultural, entendida como constelación de símbolos y formas culturales sobre las que se forman las líneas de solidaridad y fragmentación entre grupos, y su propósito es la transformación o la reproducción de estas herramientas del discurso, en el camino de la búsqueda de reconocimiento de la diferencia.

En cuarto lugar, constatamos que los contenidos culturales históricamente construidos dentro de nuestra profesión, están ligados al ideario de la Modernidad y sintetizados en sus reivindicaciones fundantes de igualdad, progreso y justicia.

\section{3.- A MODO DE PROPUESTA}

Entendemos que el saber y la intervención deben vincularse al destino colectivo. Pero ¿qué vinculación? Para el Trabajo Social de estos días, resulta eficaz la imagen de Zygmunt Bauman, que distingue entre dos tipos de intelectuales: los "intérpretes" y los “expertos". Los intérpretes, en general con mayor peso en el mundo académico, que a veces termina haciendo de sus personajes meros traductores de la experiencia de los 
sectores sociales, cayendo frecuentemente en un pesimismo fatalista o en parálisis frente a los fuertes condicionamientos estructurales. Los expertos, por su parte, pasaron a ocupar mayores espacios de poder, ligados tanto a la gestión gubernamental como al asesoramiento de organismos internacionales. Muchos de ellos, lo sabemos, se adaptaron a los malos tiempos del ajuste estructural, en algunos casos contribuyendo a sostener por izquierda aquello que los organismos internacionales venían imponiendo por derecha.

Decía Bourdieu, en su última conferencia dictada en Atenas, en el año 2001, que hay que luchar por romper con la funesta dicotomía entre quienes se consagran al trabajo científico, realizado según métodos científicos y dirigido a otros científicos, y quienes se comprometen y "sacan afuera" su saber. Lo que equivale a romper con la dicotomía entre intérpretes y expertos. Nos parece que en este aspecto, Trabajo Social tiene unas posibilidades inmensas para romper con esta oposición binaria, posibilidades que todavía no han sido totalmente exploradas ni reconocidas en su real dimensión, en orden a la posibilidad de realizar investigaciones autónomas según las reglas del trabajo científico, para poder producir un saber comprometido. El desafió actual sería, entonces, producir saberes comprometidos, ya que los nuevos movimientos sociales necesitan de los investigadores tanto como los investigadores de los movimientos sociales.

Hoy la cuestión social, que constituye el campo problemático de nuestra disciplina, adquiere ribetes dramáticos, en tanto estamos frente a un proceso de profundización de las asimetrías no sólo en las posibilidades de tener, sino de ser, como quizá no se haya visto nunca en la historia de la humanidad. Nuestra utopía, no prometeica sino razonable, radica, precisamente, en estar a la altura de la exigencia de los tiempos, aportando, tanto desde el campo de la investigación como de la intervención, ideas para hacer frente a esas asimetrías desde las nociones constitutivas de nuestra profesión, que son aquellas nociones relacionadas con los derechos sociales de ciudadanía. Y lo digo reiterando mi convicción de que los trabajadores sociales somos modernos, porque nuestra profesión surge como expresión de los postulados de la modernidad. Si quisiéramos argumentar desde la postmodernidad, primero deberíamos suicidamos como profesión.

Para terminar, si cualquier intervención, y por supuesto que también en el campo de la acción social, implica elecciones, ya que no se trata de un proceso natural que se ajusta automáticamente a la realidad; es decir, si nuestras intervenciones profesionales implican un momento de justificación de nuestras elecciones en base a lo que consideramos justo y bueno, entonces la ética seguirá constituyendo una dimensión ineludible de nuestro accionar. Mediación destinada a argumentar nuestras pretensiones en torno a lo que sea bueno y verdadero. Esto equivale a reconocer a la ética su carácter conceptual y argumentativo, su inmenso potencial como crítica de lo dado, y por lo tanto su inclusión en la agenda de quienes queremos un mundo mejor. $\mathrm{Y}$ por otro lado, equivale a reconocer a la ética como un espacio de ejercicio de la libertad, no de la prohibición. 
Estamos proponiendo entonces para la ética, una interrogación crítica de lo dado, contra aquellas posturas que expresan sintomáticamente, dentro de nuestra profesión, el sentido común neoliberal, que pregona el actual agotamiento de las energías utópicas emancipatorias.

Entonces intentemos preguntamos ¿qué implica la constitución de una instancia crítica hoy, en el actual contexto para nuestra profesión? Cómo luchar desde posiciones que interrogan críticamente la condición neofilantrópica dentro de nuestro campo? ¿Se puede reconquistar la democracia contra la tecnocracia? ¿Podemos inventar nuevas formas de trabajo colectivo, constatar necesidades y modalidades de resolución? No son estos problemas, se preguntaría Bourdieu, demasiado importantes como para dejárselos a los expertos? ¿Cómo restituir a los primeros interesados, es decir, a la población, la definición del presente y del futuro de la salud, de la educación, de la vivienda, de la cultura?

Recordemos que los sujetos sociales hablan, en el sentido de que asignan un sentido a su práctica, a su acción, y estos sentidos son diferentes, porque se construyen en un horizonte histórico, cultural y conceptual particular. Si ignoramos al otro, no hay posibilidad de palabra ni de razón. De ahí que el reconocimiento del otro exige que nuestra propia razón reflexione sobre las formas asumidas, en medio de la tensión entre el ser y el deber ser.

¿Cómo decir algo contra la actual e inusitada precarización, que produce procesos de injusticia económica y exclusión socio-cultural como quizá nunca haya conocido la historia de la humanidad? ¿Qué pueden, en este aspecto, los profesionales, los intelectuales? En el plano de nuestros compromisos societales, hay que proponerse quebrar el monopolio del pensamiento tecnocrático, restituyendo la importancia de las distintas racionalidades en el debate sobre las necesidades, esto es, restituyendo la importancia de un espacio común a distintas lógicas. En segundo lugar, comprometernos con nuestras asociaciones, que en tantos sujetos colectivos, pueden hacer públicas las condiciones actuales de vida de inmensos sectores de nuestra población, de nuestra población, entablar compromisos sostenidos en que se comparta la responsabilidad de análisis rigurosos y propositivos en tomo a la actual cuestión social. Es necesario una solidaridad real con aquellos grupos que en distintos frentes de lucha, ciertamente fragmentados, se baten por cambiar aspectos de nuestra sociedad. En este camino, creo, estaremos fructificando nuestra identidad, y a la vez preservando la esencia de nuestro oficio y el sentido de nuestra profesión, que es la construcción de justicia. 


\section{BIBLIOGRAFÍA CONSULTADA}

AQUIN N. (2002): ConjinuidaWs y rupturas de las formas de intervención con grupos y comunidades,

¿Una nueva reconceptualización? En el libro Nuevos escenarios y práctica profesional. Una mirada crítica desde el Trabajo Social. Espacio Editorial, Buenos Aires.

Auge, M. (1998), Los no lugares espacios del anonimato -Una antropología de la Sobremodernidad-, Gedisa, Barcelona.

COlombo E. (1993)- El imaginario social. Editorial Altamira, Montevideo.

GEERTZ, C. (1995), La interpretación de las culturas; Gedisa, Barcelona, España.

GONZÁlez C., AQUín N. (1992)-. El Trabajo Social en relación a las Politicas Sociales: algunos interrogantes y posibles respuestas. En Revista Acto Social N' 1 - Córdoba.

KYMLIEKA, W. (1996) Ciudadanía Multicultural -Estado y Sociedad- Barcelona, España.

parís pombo, M. (1 990) Crisis e identidades Colectivas en América Latina, México. Severini S. (comp.) (2002): Trabajo Social y mundializacion. Espacio Editorial, Buenos Aires. 